\title{
Sobre a oportunidade de um legado olímpico para o Rio
}

\author{
Guilherme Lassance \\ Universidade Federal do Rio de Janeiro \\ Contato: glassance@gmail.com
}

A reinauguração da Praça Mauá, localizada no centro da cidade do Rio de Janeiro, nos lembrou, com pompa e circunstância, a condiçáo de cidade e sociedade desigual com a qual nos acostumamos desde sempre a conviver.

O projeto é parte integrante de uma série de açôes que podem ser, de certa forma, consideradas como legítimas herdeiras da "política de distribuição de investimento no território municipal que, sistematicamente, privilegiará a área central da cidade e os bairros onde reside a população de maior poder aquisitivo da Zona Sul e parte da Zona Norte, em detrimento dos chamados subúrbios" (FERNANDES, 2010, p.15). No Rio, a origem dessa política coincide, segundo o autor, com o momento seguinte à Reforma Passos em que se tratou, então, de dar solução "ao urgente problema das habitaçôes na capital da república” (BENCHIMOL apud FERNANDES, 2010, p.14), utilizando o subúrbio "para tirar da cena urbana as classes populares da cidade", negando-lhes "até mesmo a possibilidade de estar, no nível das representaçôes, dentro da cidade" ${ }^{1}$. Assim, a própria persistência do uso da palavra subúrbio constrói, segundo o autor, "um dos eixos do imaginário e da ideologia da segregação socioespacial na geografia do Rio de Janeiro" (FERNANDES, 2010, p.8), no sentido em que utiliza a referência a um termo que, convencionalmente, remete à ideia de subordinação política, econômica e cultural de arrabaldes ou vizinhanças da cidade caracterizadas pela descontinuidade de construçóes.

\section{Citando MORRIS (1973), FERNANDES} nos lembra assim que, "na linguagem do Rio, o termo suburbano é pejorativo e indica falta de cultura e sofisticação" (2010, p.12). Daí a urgência de ultrapassarmos a dicotomia centroperiferia e as representaçóes pejorativas que nela se estabelecem, criando nova atratividade para as áreas já urbanizadas e infraestruturadas mas ainda negativamente percebidas como "subúrbio" (leia-se "sub-cidade", "não-cidade").

Essa nossa relação específica com o conceito de subúrbio explica a dificuldade de aplicar diretamente ao Rio as referências da regeneração urbana em bairros centrais, principal mantra da definição de "cidade sustentável" (LEITE $\&$ AWAD, 2012) a elas associada. De fato, no mundo dito "desenvolvido", principalmente norte-americano, os subúrbios são geralmente ricos, enquanto os centros concentram áreas monofuncionais de escritórios (o chamado CBD - Central Business District), rodeadas de antigos distritos industriais decadentes que se tornaram pobres e degradados. É nessas periferias imediatas do centro que as operaçóes de regeneração têm sido desenvolvidas no sentido de atrair uma jovem

1. "O conceito carioca de subúrbio expressa uma busca exacerbada de distinção e exclusão social que caracterizam a República e que infelizmente pouco mudou." (FERNANDES, 2010, p. 15). 
população de alta renda, vendendo-lhe um "estilo de vida” diferenciado graças à criação de novas tipologias residenciais resultantes, entre outros, da renovação de instalaçóes industriais ociosas.

Ora, no Rio, existem dois grandes obstáculos a tais projetos: primeiramente, o nosso subúrbio concentra, em sua maioria, uma população de baixa renda que, não tendo como arcar com os custos elevados de um produto imobiliário mais central, não constitui o "perfil de consumidor" desejado pelo mercado. Diferentemente de algumas realidades europeias, como a francesa, por exemplo, a administração pública brasileira também não tem meios para subsidiar uma política de habitação social capaz de equilibrar e regular os ímpetos do mercado imobiliário e, assim, garantir um nível suficiente de "mixidade" social nas áreas mais centrais e valorizadas da cidade como meio de combater a expansão das periferias carentes (sobre isso, vale lembrar que nossos governos têm, inclusive, atuado no sentido contrário, promovendo a habitação de baixa renda - como, por exemplo, no Programa Minha Casa Minha Vida do Governo Federal - em áreas distantes, pouco urbanizadas e mal infraestruturadas, corroborando, assim, com o histórico processo de segregação socioespacial).

Em segundo lugar, o mercado imobiliário carioca, que vive há décadas da reproduçáo de fórmulas concebidas para geração do maior lucro, tornouse adverso à inovação tipológica necessária para atrair consumidores de maior renda, capazes de pagar por um imóvel em bairros centrais, mas que, hoje, preferem a segurança e a liquidez de empreendimentos localizados nas áreas já valorizadas junto à orla oceânica - atitude conservadora que acaba perenizando uma oferta pouco diversificada (a proximidade da praia, a vista para o mar, as amenidades e a paisagem natural de lagoas, montanhas e florestas acentuam, no Rio - como nas demais metrópoles brasileiras situadas no litoral -, o fenômeno da polarização socioespacial). Nos raros exemplos em que o mercado lançou produtos em áreas centrais, verificou-se a reproduçáo de modelos barateados dos condomínios da periferia praiana e o total desperdício da oportunidade de se imaginar e valorizar um modo diferenciado de se morar. Com isso, o que se produz junto ao centro é mais área construída de escritórios, único programa capaz de concorrer pelos altos custos dos terrenos inflacionados por operaçóes consorciadas como a do Porto Maravilha. O resultado é a concentração ainda maior da oferta de emprego sem moradia no centro e da moradia sem emprego na periferia, situação que acaba acentuando, também, o problema da mobilidade.

Nesse sentido, as iniciativas e projetos de regeneração urbana teriam que favorecer a criação de centralidades alternativas e pujantes no subúrbio, e não num centro já hipervalorizado, inclusive para aliviar esse centro que vive hoje sob alta pressão. Essa situação vem, de fato, afetando a integridade física do patrimônio de alto valor artístico e cultural ali situado.

Há, ainda, que se considerar, nessa mesma conta, a degradaçáo dos bairros ditos "de passagem" cuja paisagem, ambiência, patrimônio e modos de vida foram sendo degradados pela sucessiva implantação de linhas de trem, viadutos e, mais recentemente, corredores expressos de ônibus que os atravessam impunimente e os segregam espacialmente em prol da necessária mobilidade, mas cujos modais mostram-se altamente ineficientes e, ao mesmo tempo, inevitavelmente saturados já que funcionam basicamente em mão única e em horários restritos, determinados pelos fluxos de chegada matinal ao local trabalho no centro da cidade (inbound) e de retorno vespertino ao lugar de moradia na periferia (outbound).

Acreditamos, assim, que somente com uma real mudança na área-foco das políticas de investimento como na capacidade de se considerar a perspectiva de uma redistribuição das funçôes centrais na 
cidade é que o caminho da regeneração urbana poderia ser então perseguido. Mas se a presença de um patrimônio histórico excepcional tem sido usada muitas vezes como chamariz das operaçóes localizadas no centro, como fazer do nosso subúrbio carente e degradado algo atraente e desejado, capaz de rivalizar com os atrativos naturais da orla praiana, redistribuindo, assim, mais equitativamente as riquezas, ofertas de emprego e serviços de qualidade nos territórios não apenas municipais, mas também metropolitanos do Rio de Janeiro?

Em um texto redigido e publicado em um momento em que se tratou de reconstruir a área do World Trade Center em Nova Iorque que havia sido afetada pelo atentado às torres gêmeas, o crítico norte-americano SORKIN (2003) nos fornece uma pista. A cidade de Nova Iorque possui, como no Rio, uma periferia majoritariamente carente e totalmente dependente do transporte público de massa para se deslocar diariamente em direção a Manhattan. Apesar de mais densa do que a carioca, a rede de metrô desempenha em Nova Iorque um papel semelhante ao dos trens de subúrbio no Rio, que é o da manutenção de uma situação de flagrante segregação socioespacial e polarização funcional. De fato, como no Rio, a rede de transportes de massa existe, basicamente, para interligar os polos de negócios situados em Manhattan que concentram a maior oferta de empregos às vastas e cada vez mais longínquas periferias-dormitório dos demais boroughs (Bronx, Queens, Brooklyn e Staten Island). Apostando na capacidade de se tirar melhor partido da infraestrutura já instalada, o autor vislumbra um futuro policêntrico para a cidade de Nova Iorque, graças ao fortalecimento de centralidades a partir de identidades locais, algumas já existentes e tradicionais, outras a serem criadas, e sua transformação em "bairros autossuficientes, nos quais as pessoas fossem a pé ao trabalho, à escola, à recreação e às atividades culturais" (SORKIN, 2003, p.25). À semelhança do que ocorre no caso das redes regionais de cidades na Europa (como por exemplo, na Randstad holandesa), a infraestrutura metroferroviária e os demais modais troncais de transporte coletivo passariam, assim, a funcionar para deslocamentos de maior distância, induzidos por necessidades eventuais associadas a uma lógica de complementaridade de serviços entre os diferentes polos de atividade, e não mais em uma relação quotidiana de estreita dependência entre centro e periferia.

\section{Uma oportunidade para a reinvençáo da periferia no Rio de Janeiro}

A urbanização da vasta planície oceânica da Barra da Tijuca, para onde foi direcionada a parte mais expressiva dos investimentos relacionados aos Jogos Olímpicos de 2016, poderia ser, de certa forma, comparada àquela que outrora dera origem à urbanização dos subúrbios praianos da Zona Sul. Ela segue uma lógica basicamente semelhante, impulsionada pelas pressôes de dominante residencial do mercado imobiliário e da construção civil, e influenciada por modelos importados, definidos pelo próprio mercado como atual "sonho de consumo" da parcela de maior poder aquisitivo da populaçáo. Entretanto, instalando-se em um território muitas vezes maior do que aquele da cidade de quatro séculos que a precedeu, o desenvolvimento da Barra inaugura uma nova espécie de paradigma urbanístico. Uma enorme planície que se prestou bem aos anseios do urbanismo modernista e, é claro, do mercado imobiliário que o promoveu. De fato, e mesmo que modificado pela atual ocupação urbana, é preciso sublinhar aqui que os princípios previstos pelo plano usado para urbanizá-la, idealizado por Lúcio Costa, propunham ali um novo estilo de vida. Assim, a região da Barra ganhou atratividade não apenas pela praia e proximidade do mar, mas, também, e sobretudo, por ser radicalmente diferente das demais áreas da cidade. 
O mercado imobiliário soube, assim, capitalizar o sonho modernista de um novo estilo de vida naquela vasta e "virgem" planície, articulando-o a referências importadas e com ele sintonizadas, como principal argumento de sua estratégia de marketing. ${ }^{2}$

Por que, então, não operar de forma análoga para reinventar um sonho de consumo alternativo para as periferias norte e oeste, hoje desvalorizadas e socioeconomicamente segregadas? Afinal, como nos lembra ASCHER (2010, p.136-138), na cidade plural contemporânea, coexistem diferentes tipos de ambiente urbano e modos de vida a eles associados - um amplo leque que vai daqueles que preferem viver na hiperdensidade de áreas centrais aos que buscam a vida mais campestre nas margens ainda rurais da cidade. Isso significaria a possibilidade de se pensar e desenvolver ambientes de vida urbana e atividade econômica diferenciados e, por isso mesmo, complementares, concebendo produtos imobiliários especificamente voltados para cada um desses diferentes tipos de consumidores e "cidades".

Nesse sentido, vale aqui lembrar a crítica feita por SOLÀ-MORALES (1995, p.109-125) à vinculação estreita que costuma ser estabelecida entre a própria construção do conceito de lugar e a cidade de um passado histórico romantizado enquanto única e soberana guardiã da memória coletiva. Essa vinculação torna-se insustentável ao tratarmos de grandes aglomeraçóes urbanas como o Rio. Assumila como tal, significaria afirmar que, desde então, a cidade não teria produzido história digna de ser respeitada e valorizada, uma atitude denunciada por Rem Koolhaas e sua equipe na Bienal Internacional de Arquitetura de Veneza em 2010. $\mathrm{Na}$ ocasiáo, o conceito de "cronocaos" foi usado para discutir as derivas das políticas de preservação do patrimônio, movidas pelo afá de se privilegiar o que as sociedades tradicionais produziram como cidade e arquitetura em um passado pré-moderno, obliterando, assim, todo o registro cultural das geraçóes que as sucederam, dentre as quais inclui-se a nossa própria.

Quando nos referimos ao centro histórico da cidade como lugar da memória, vale, portanto, nos perguntar de que "memória" estamos falando exatamente. Outra pergunta relevante para o nosso propósito aqui diz respeito ao grau de comunidade cultural que, de fato, existiria entre um morador do privilegiado Leblon e outro do segregado Bangu. Afinal, teríamos ainda alguma ilusão de que os famosos cartôes postais do Rio de Janeiro representariam mesmo um só tipo de cidade, paisagem urbana e modo de vida? E mais: caberia, nesse sentido, dizer que o que é hoje considerado como alto nível de qualidade de vida no Leblon serviria de referência para se pensar o futuro de Bangu? Se dissermos náo, estaríamos, então, refutando a hipótese de, um dia, também alcançarmos um alto nível de qualidade de vida em Bangu sem para isso termos que, necessariamente, transformá-la em um Leblon? Isso implica em diversificar nossas referências de qualidade, recusando a atitude hipócrita que consiste em nos contentar apenas em providenciar os serviços básicos e viabilizar melhor acesso das populaçôes residentes dessas periferias carentes de tudo às áreas mais valorizadas e bem equipadas da cidade.

Ora, é justamente essa discrepância geográfica de investimentos e a dificuldade de reconhecimento por parte da administração pública, do papel econômico estratégico que áreas ainda não ou pouco ocupadas podem desempenhar para a cidade se permanecerem assim, que a situação acaba se transformando no principal combustível da expansão urbana não planejada e capitaneada pelo

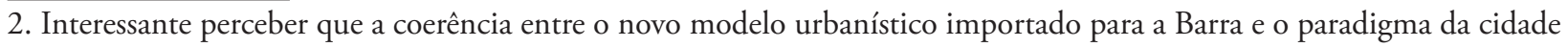
modernista utilizado por Lúcio Costa para planejar sua ocupação tem sua origem no aproveitamento que a indústria norteamericana de bens de consumo (automobilística e de eletrodomésticos principalmente) já havia feito dessas mesmas teses no sentido da própria construção e promoção da referência em questão. 
mercado imobiliário, seja ele formal ou informal. Atraídos pela perspectiva de maximização de suas margens de lucro, incorporadores e construtoras partem em busca dos terrenos de menor custo para seus empreendimentos residenciais, justamente aqueles que se encontram, hoje, situados nas periferias mais distantes e desvalorizadas, por serem áreas sem papel estratégico ou econômico claramente definido para a cidade, sendo, por isso, desprovidas de qualquer infraestrutura urbana ou serviço, e também muito afastadas dos polos geradores de empregos. Isso ocorre tanto com produtos imobiliários destinados à classe média e média alta na periferia oceânica, quanto em projetos ditos de "interesse social", como no caso do Programa Minha Casa Minha Vida, que vem, impunemente, povoando zonas ainda rurais sem nenhuma articulação com elas.

Os problemas ambientais e as deficiências da infraestrutura sanitária e de transporte, comumente apontados como efeitos diretos da expansão urbana, são invocados para "criminalizar" o próprio conceito de urbanização menos densa, negando-lhe, assim, qualquer valor e, por tabela, a capacidade dessas mesmas áreas de se desenvolverem de maneira diferenciada e complementar ao resto da cidade.

Assim, ao mantê-las em sua condição de "erro", tal visão acaba contribuindo para a manutenção da situação precária em que se encontram, reforçando sua atratividade para o mercado imobiliário. Nesse sentido, podemos dizer que os problemas ambientais e insuficiências da infraestrutura são, na realidade, decorrências diretas desse ciclo vicioso propulsado pela inabilidade da instância planejadora em projetar funçóes urbanas suficientemente robustas para agregar valor econômico e papel estratégico a essas periferias, e torná-las, assim, mais capazes de resistir à ação predatória do mercado imobiliário e da urbanização selvagem.

\section{Infraestrutura de mobilidade e geraçáo de centralidades alternativas}

Nesse sentido, a decisão de implantar a quase totalidade das instalaçóes destinadas aos Jogos Olímpicos de 2016 na Barra da Tijuca pode ser criticável por ter sido, em grande parte, resultante das mesmas pressóes associadas a esses processos predatórios aos quais nos referimos acima.

Entretanto, tal decisão nos permite, aqui, não propriamente reconhecer seu papel para o sucesso do atual plano estratégico da cidade, mas imaginála muito mais como uma oportuna e, talvez, até mesmo inesperada contribuição para um potencial redirecionamento do paradigma de planejamento do município do Rio de Janeiro e sua região metropolitana.

Para explicar nosso raciocínio, é preciso lembrar o destaque que a prefeitura tem dado à mobilidade como principal legado dos Jogos, justificando, assim, sua decisão de instalar os Jogos em uma região periférica e antes muito carente nesse aspecto. Floráo do novo Plano de Mobilidade Urbana (PMU), as novas linhas de BRT (Bus Rapid Transport) têm sido, no entanto, alvo de críticas contundentes sobre sua pertinência como solução de transporte coletivo, tanto por parte de especialistas, quanto pela própria populaçáo que as utiliza. Todos denunciam o rápido esgotamento da capacidade de público atendido pelas linhas já implantadas, sobretudo nos horários de pico e, também, a baixa eficiência desse tipo de modal para percorrer as grandes distâncias que separam os locais de residência e trabalho de seus usuários. Se o princípio da faixa segregada de circulação constitui uma nítida melhoria em relação às condiçóes anteriores de transporte, a concepção do sistema parece, no entanto, desprezar ou mesmo desperdiçar o papel das infraestruturas de transporte enquanto dispositivos potencializadores de centralidades econômicas distribuídas em rede. 
A falta de articulação urbana de suas estações e vias segregadas atestam sua incapacidade de contribuir com a criação de espaços públicos significantes, quando náo resultam na eliminação daqueles poucos ambientes que desempenhavam algum papel nesse sentido. Tal situaçáo denuncia as intençôes de um projeto de infraestrutura eminentemente voltado para o atendimento da pura necessidade funcional de deslocamento quotidiano entre residência e trabalho, reproduzindo, assim, o processo de segregação socioespacial e afirmação da condição de dormitório dos bairros situados na periferia da cidade. ${ }^{3}$

Apesar dessas deficiências de concepção, acreditamos que seja possível enxergar nas novas infraestruturas de transporte projetadas em regióes distantes do centro urbano um importante legado olímpico para a cidade. Na medida em que essas infraestruturas foram previstas para atender as sedes dos Jogos na Barra e em Deodoro, a rede para elas criada tem, nesses sítios ou próximo a eles, seus principais nós e estaçôes terminais, seja como origem-destino das viagens, seja como pontos de baldeação entre linhas e modais de transporte. Além disso, sua implantação em grandes e ainda raras reservas fundiárias de domínio público e relativamente livres de ocupação urbana (como no caso das vastas áreas militares de Deodoro) confere suficiente flexibilidade e envergadura espacial para viabilizar a criação de equipamentos e serviços de escala metropolitana. Reúnem-se, assim, condiçôes favoráveis à definição de um plano possível de distribuição geográfica mais equânime da oferta de empregos, propulsando o desenvolvimento de uma rede de centralidades alternativas e efetivamente complementares ao centro da cidade.

É preciso, portanto, frisar que estamos tratando aqui de um tipo de centralidade bastante diferente da que costuma estar associada ao conceito de “centro de bairro" usado pela legislação para se referir à possibilidade de implantação de atividade comercial e usos não residenciais de caráter local, ao longo de corredores de trânsito ou ao redor de estaçôes de transporte.

O padrão de centralidade que pode ser gerado a partir das estruturas olímpicas se distingue também daquelas que, por circunstâncias favoráveis locais ou regionais, se desenvolveram de forma espontânea e não planejada, adquirindo certa expressividade na escala mais abrangente da cidade. Algumas delas foram intensificadas pela integração às novas linhas de BRT, como no caso de Madureira, cuja proeminência também se beneficiou com a recente criação do parque de mesmo nome, raro investimento público em um equipamento de lazer de escala metropolitana em todo o subúrbio carioca. O notável sucesso desse projeto e o efeito de valorização por ele produzido para toda aquela área permite sublinhar a importância do fator escala e a dimensão simbólica e ele vinculada na produção de centralidades alternativas ao centro histórico. Apesar disso, Madureira constitui o que poderíamos chamar de "centralidade esgotada". Como muitos outros centros de bairro situados em entroncamentos viários e ferroviários historicamente importantes para a cidade, sua capacidade para continuar se desenvolvendo esbarra, justamente, na inércia que lhe é hoje imposta pelo seu próprio processo de formação histórica. Nesses subúrbios consolidados, a microparcelização do solo resultante da função residencial original do bairro-dormitório não somente aponta para a condição física precária de um parque imobiliário que foi se adaptando de maneira lenta e informal às oportunidades da atividade comercial, mas revela, também, a grande complexidade inerente a qualquer plano que vise a remodelação urbanística desses centros suburbanos a fim de transformá-los em polos de maior grandeza.

3. Podemos dizer que a criação de linhas de BRT na Zona Oeste vem, inclusive, viabilizando e intensificando a implantaçáo de empreendimentos imobiliários em áreas isoladas da cidade. 
Vale, de fato, lembrar que intervençóes urbanas de grande envergadura e qualidade artística foram essenciais à afirmação e manutenção das funçôes centrais do núcleo histórico da cidade ao longo do tempo, inclusive para tornar o Rio menos dependente e subordinado à antiga metrópole colonial. Entretanto, elas se restringiram sempre a ele, ficando o restante da cidade basicamente entregue à urbanização por parcelamento genérico de lotes com dimensões reduzidas e caráter residencial. Daí a dificuldade, hoje, para fazer com que, em meio a essa urbanidade "sem rosto nem índole", onde se justapóem impunemente padróes individuais de ocupação amparados por códigos urbanísticos desarticulados, possam surgir polos de atividade e representatividade com suficiente magnitude para serem capazes de transcender a escala de seus respectivos contextos locais. Por isso, é uma oportunidade ímpar que a realização dos Jogos Olímpicos na Zona Oeste oferece para uma mudança na forma de pensarmos o desenvolvimento da cidade como um todo.

\section{Referências bibliográficas}

ASCHER, François. Les nouveaux principes de l'urbanisme, suivi de Lexique de la ville plurielle. Paris: l'Aube, 2010.

BENCHIMOL, Jaime L. Pereira Passos: um Haussmann tropical. Rio de Janeiro: Secretaria Municipal de Cultura, 1992.

FERNANDES, Nelson da N. O conceito carioca de subúrbio: um rapto ideológico. Subúrbios Cariocas, Revista da FAU-UFRJ, n. 2, 2010.

LEITE, Carlos; AWAD, Juliana di C. M. Cidades sustentáveis, cidades Inteligentes: desenvolvimento sustentável num planeta urbano. Porto Alegre:

Bookman, 2012.

MORRIS, Frederic. A geografia social do Rio de Janeiro. Revista Brasileira de Geografia, n. 35. Rio de Janeiro: IBGE, 1973.
SOLÀ MORALES, Ignasi de. Lugar: permanencia o producción. In: Diferencias. Topografía de la arquitectura contemporánea. Barcelona: Ed. Gustavo Gili, 1995. p. 109-125.

SORKIN, Michael. O centro não se sustém. De tudo um pouco. Sobre edifícios e cidades. São Paulo: Martins Fontes, 2014, p. 20-27 (originalmente publicado em Sorkin, M.; Zujkin, S. (orgs.) After the World Trade Center: Rethinking New York City. Nova Iorque: Routlegde, 2003). 